\title{
Face recognition memory: Distribution of false alarms
}

\author{
ALVIN G. GOLDSTEIN, BLAIR STEPHENSON, and JUNE CHANCE \\ University of Missouri, Columbia, Missouri 65201
}

The responses of subjects in six face recognition memory studies were analyzed to determine whether false alarms (FAs) to distractors were randomly distributed. Evidence from every study strongly supports the conclusion that FAs are nonrandom. For reasons still unclear, some faces are often mistakenly selected as targets, others are never selected. Possible explanations of these findings are discussed.

In laboratory studies, observers' recognition memory performance for faces following a single brief exposure is typically characterized by fairly large numbers of correct identifications (hits), smaller but consistent numbers of errors of commission (false alarms), and errors of omission (misses). It is more than likely that both kinds of errors occur in criminal investigations, but for obvious reasons false alarms (FAs)-misidentifying innocent individuals-are more newsworthy when discovered and much more troublesome than misses. Nonsystematic observations by at least two investigators (Cross, Cross, \& Daly, 1971; Goldstein, in press) suggest that some distractor faces "attract" more than their statistical share of FAs. The single purpose of this research was to discover whether FAs are distributed randomly among distractors in recognition memory experiments.

Both theoretical and practical advantages would be derived from more detailed knowledge regarding responses to visual distractors. If, in fact, occasional distractor stimuli attract erroneous responses in a nonrandom fashion, and this kind of response bias could be shown to occur with some generality, it might afford a method which could be used to discover what is the "content" of the stored information carried by a subject who had viewed target faces in an earlier study session. That is, if FAs are not distributed randomly, then faces erroneously selected as targets may upon appropriate analysis tell us something about the stimulus the subject was "looking for" in the test session. Moreover, nonrandom responses to distractors might offer a solution to the puzzling fact that on occasion several eyewitnesses in a criminal case have identified the same innocent person as the culprit (Wall, 1965).

\section{METHOD}

Five investigations were conducted using standard procedures for testing recognition memory. Racially mixed target faces were presented first in a study session, then in an immediately following test session interspersed among distractor faces. In both sessions, faces were presented singly; in the test trials the subject had to decide for each stimulus whether it was a target face (old) or a distractor face (new). Face stimuli were achromatic full-face portraits obtained from high school yearbooks and placed on slides. All photographs were selected to reduce nonfacial cues for recognition. Subjects were white college students. Number of targets, number of distractors, length of study-test interval, and task instructions were varied to assess their effect on the distributions of FAs. These procedural variations will be described below, where appropriate. All data were analyzed by the Cochran Q test (Siegel, 1956; Winer, 1962). Data from a face recognition experiment (Malpass \& Kravitz, 1969) performed by an investigator at a laboratory other than the authors' have been included in this report (as Study 6), but these were merely tabulated, not analyzed. ${ }^{1}$

\section{RESULTS}

\section{Study 1}

During the study session 9 subjects were shown 20 target faces (17 white, 3 black), each for $3 \mathrm{sec}$. Ninety distractor faces (12 black) plus the 20 targets were displayed for $7 \mathrm{sec}$ each in the test session; subjects were given no information about the number of targets or distractors, but were merely asked to identify the old pictures.

Frequencies of the 102 FAs (Table 1) were distributed in a significantly nonrandom manner (Cochran $\mathrm{Q}=$ $119.66,89 \mathrm{df}, \mathrm{p}<.05)$. Although overall hit rate was $74 \%, 2$ of the 20 targets were correctly identified by less than half the subjects, and another was correctly identified by only one-third of the subjects. Note that in these latter instances, the number of hits was equal to the number of FAs elicited by several distractors.

Interestingly, 2 of the 10 distractors which attracted more than three FAs were black faces. Recognition memory performance for other-race faces is known to be poorer than for own-race faces (Chance, Goldstein, \& MacBride, 1975; Malpass \& Kravitz, 1969). Although poor recognition performance could be expected to be correlated with a slightly higher number of false alarms, poor performance does not in itself imply nonrandom FAs.

\section{Study 2}

Eight target faces (1 black), randomly selected from 
Table 1

Responses to Distractor Faces in Six Studies

\begin{tabular}{|c|c|c|c|c|c|c|c|c|c|c|c|}
\hline \multirow[b]{2}{*}{ Study } & \multicolumn{7}{|c|}{ Frequency of False Alarm Responses } & \multirow[b]{2}{*}{$>7$} & \multirow[b]{2}{*}{$\begin{array}{c}\text { Expected } \\
\text { Frequency* }\end{array}$} & \multicolumn{2}{|c|}{ Total } \\
\hline & 0 & 1 & 2 & 3 & 4 & 5 & 6 & & & $\begin{array}{l}\mathrm{N} \text { of Dis- } \\
\text { tractors }\end{array}$ & $\begin{array}{l}\mathrm{N} \text { of } \\
\text { FAs }\end{array}$ \\
\hline 1 & 31 & 30 & 19 & 6 & 4 & & & & 1.1 & 90 & 102 \\
\hline 2 & 26 & 13 & 4 & 3 & 2 & 2 & & & .90 & 50 & 48 \\
\hline 3 & 27 & 9 & 10 & 3 & & & 1 & & .88 & 50 & 44 \\
\hline 4 & 28 & 14 & 4 & 1 & 3 & & & & .70 & 50 & 37 \\
\hline 5 & 24 & 22 & 12 & 12 & 3 & 1 & 1 & $5 * *$ & 2.02 & 80 & 162 \\
\hline Malpass & 9 & 17 & 17 & 12 & 7 & 5 & 8 & $12 \dagger$ & & & \\
\hline
\end{tabular}

Note-Read this table as follows: In Study 2, 26 distractor faces were never judged to be targets, 13 distractors were each selected once as targets, 4 were each selected twice. . . and 2 were selected five times.

*This value is computed from FAs/number of distractors and represents an estimate of the expected frequency with which each distractor would be erroneously selected if errors were completely random.

${ }^{* *}$ These five faces were identified as targets $9,11,11,11$, and 14 times.

tSix of these faces were misidentified 7 times, two were misidentified 8 times, and the remaining four faces accounted for 9,10 , 15 , and $16 \mathrm{FAs}$.

the 20 targets of Study 1, and 50 distractor faces (6 black), also selected from Study 1, were shown to 15 subjects. Each target was exposed for slightly less than $2.5 \mathrm{sec}$ during the study session. Instructions read to the subjects at the beginning of the test session cautioned them to limit their number of "seen-before" responses to approximately eight, the actual number of target faces.

Even though the number of FAs was reduced in comparison to Study 1, presumably in response to the "cautious" instructions and slightly shorter observation time, frequencies of FAs (Table 1) were again distributed nonrandomly $(\mathrm{Q}=105,49 \mathrm{df}, \mathrm{p}<.01)$. Overall accuracy of performance was only $58 \%, 16 \%$ less than in Study 1. Although statistical comparisons between experiments were not attempted at this time, it is interesting to note that in both experiments the same four faces "attracted" three or more FA responses.

\section{Study 3}

All experimental conditions and stimuli of Study 2 were repeated in this experiment, using 13 new subjects, except that information about the number of old faces displayed in the test session was not offered at any time to the subjects.

Hit rate returned to $72 \%$. Distribution of 44 FAs was nonrandom $(\mathrm{Q}=89.63,49 \mathrm{df}, \mathrm{p}<.01)$. The absolute number of FAs was rather small; only four distractors were erroneously selected as targets by three or more subjects (Table 1).

\section{Study 4}

All conditions of this experiment were identical to Study 3 . Only the subjects (13 new ones) and the eight targets (former distractors in Study 1) differed from Study 3.

Hit rate was $74 \%$, and total number of FAs was 37. Frequency of FAs was nonrandomly distributed among the 50 distractors $(\mathrm{Q}=68.40,49 \mathrm{df}, \mathrm{p}<.05)$.

\section{Study $5^{2}$}

A completely new set of faces was presented to 40 subjects with instructions informing them of the subsequent recognition test 1 week later. In the study session, 20 targets were each exposed for $3 \mathrm{sec}$. These 20 faces were randomly dispersed among 80 distractors in the recognition session. Subjects were asked to restrict their number of "old" responses to 20.

A total of 162 FAs were recorded to the 80 distractors, and the distribution of these errors, shown in Table 1, was grossly nonrandom $(\mathrm{Q}=311.99,79 \mathrm{df}$, $\mathrm{p}<.001)$.

\section{Study 6}

False alarm data (for white faces) from an experiment performed by Malpass and Kravitz (1969) have been tabulated and are shown in the last row of Table 1 . No statistical analysis was computed for this data. Nonetheless, distribution of FAs across frequency categories is similar to the distribution of the data obtained in Studies 1 through 5 , even though the investigators used different face stimuli, exposure times $(1.5 \mathrm{sec})$, targetdistractor ratios, and instructions.

\section{DISCUSSION}

These results establish the existence of a phenomenon heretofore only mentioned in reports of face recognition investigations (Cross et al., 1971; Goldstein, in press). False alarms in response to a series of distractor faces are distributed nonrandomly. For unknown reasons, certain faces within the series described above either are never mistaken or are often mistaken for a target face. This finding seems to be fairly general; changing targets, distractors, study-test interval, experimental technique, instructions, investigators, and so on, seems to have little effect on its occurrence. Although this result may come as no surprise, its precise explanation is far from clear.

One explanation comes to mind almost immediately, but careful examination of the hypothesis reveals logical difficulties. If in every series of distractor faces there are a few with one or more features similar to features of one or more target faces, then all the subject is doing when he commits a FA is confusing 
the feature of the distractor with the feature of the target. But why should the subject select the distractor and not the target if the subject's "image" of the target was clear enough in the first place to fool him into choosing the distractor? Why select a face similar to the target and miss the target? Or does the subject actually miss the target when he selects a distractor? That is, is selection of a particular distractor perfectly correlated with missing a particular target? Could it be the case that subjects select distractors which are similar in some way to a target they have already correctly judged as familiar, but by making the choice the subject does not "cancel" the search? In this view, a distractor is chosen not in place of a target, but in addition to a target. Obviously, further research is necessary to answer these questions.

A second hypothesis also has intuitive appeal. Perhaps the "attractive" distractor faces possess an "everyman" quality because each includes one, two, or more facial features which are similar to many other faces in the general population. Thus, for example, if the mouth and forehead of one of the distractors is similar in shape to the modal mouth and forehead, then this face may look "familiar" because of the subject's preexperimental experience.

Is there a real-life counterpart to this phenomenon? Perhaps, but we can only speculate about the answer to this question. Surely, if certain faces (targets) "cause" other faces (distractors) to be erroneously selected, then analogous errors could occur in a criminal investigation if eyewitness evidence were involved. Interestingly, experimental evidence is readily available which demonstrates that other unique responses are made to faces for unknown reasons. Shoemaker (Shoemaker, South, \& Lowe, 1973), for example, has shown that subjects will consensually label randomly selected male faces as "murderer," "rapist," or other deviant. In other words, subjects seem to share a stereotype for "a murderer" and they can "find" the stimuli that match that stereotype in certain face stimuli.

\section{REFERENCES}

Chance, J., \& Goldstein, A. G. Recognition of faces and verbal labels. Bulletin of the Psychonomic Society, 1976, 7, 384-386.

Chance, J., Goldstein, A. G., \& McBride, L. Differential experience and recognition memory for faces. Journal of Social Psychology, 1975, 97, 243-253.

Cross, J. F., Cross, J., \& Daly, J. Sex, race, age and beauty as factors in recognition of faces. Perception \& Psychophysics, 1971, 10, 393-396.

Goldstein, A. G. The fallibility of the eyewitness: Psychological evidence. In B. D. Sales (Ed.), Psychology in the legal process. New York: Spectrum, in press.

Malpass, R. S., \& Kravitz, J. Recognition for faces of own and other race. Journal of Personality and Social Psychology, 1969, 13, 330-334.

Shoemaker, D. J., South, D. R., \& Lowe, J. Facial stereotypes of deviants and judgments of guilt or innocence. Social Forces, 1973, 51, 427-433.

SIEGEL, S. Nonparametric statistics for the behavioral sciences. New York: McGraw-Hill, 1956.

$\mathrm{W}_{\mathrm{ALL}}$, P. Eyewitness identification in criminal cases. Springfield, Ill: Charles C Thomas, 1965.

WINER, 'B. J. Statistical principles in experimental design. New York: McGraw-Hill, 1962.

\section{NOTES}

1. I would like to thank Roy Malpass for sharing his data.

2. For analysis in the present investigation, data of 40 subjects were obtained from Groups $A$ and $B$ of an experiment reported earlier (Chance \& Goldstein, 1976).

(Received for publication January 21, 1977.) 